\title{
Homotopy Analysis Method to Walter's B fluid in a vertical channel with porous wall
}

\author{
A.A. Joneidi • G. Domairry • M. Babaelahi
}

Received: 13 October 2008 / Accepted: 16 March 2010 / Published online: 9 June 2010

(C) The Author(s) 2010. This article is published with open access at Springerlink.com

\begin{abstract}
In this research the steady three-dimensional flow of a Walter's B fluid in a vertical channel with porous wall, through which the fluid is injected uniformly into the channel through one side of the channel, is studied analytically using Homotopy Analysis Method (HAM). The channel is assumed to be infinite and uniform. The effects of the elasticity of the fluid on the flow and heat transfer on the walls of the channel are discussed.
\end{abstract}

Keywords Homotopy Analysis Method (HAM) • Velocity equation · Walter's B fluid · Vertical channel · Porous wall · Viscoelastic fluid

$\begin{array}{ll}\text { Nomenclature } \\ c_{p} & \text { Specific heat at constant pressure } \\ \boldsymbol{e} & \text { Rate of strain tensor } \\ \boldsymbol{g} & \text { Gravitational acceleration vector } \\ \boldsymbol{I} & \text { Identity tensor }\end{array}$

A.A. Joneidi

Department of Mechanical Engineering, Eindhoven

University of Technology, Eindhoven, Netherlands

G. Domairry $(\bowtie)$

Department of Mechanical Engineering, Babol University

of Technology, Babol, Iran, P.O. Box 484

e-mail: amirganga111@yahoo.com

M. Babaelahi

Department of Mechanical Engineering, K.N. Toosi

University of Technology, Tehran, Iran

$\begin{array}{ll}k & \text { Thermal conductivity } \\ k_{0} & \text { Short memory coefficient } \\ L, B, D & \text { Dimensions of the channel } \\ \mathrm{Pe} & \text { Peclet number } \\ P & \text { Pressure } \\ P_{x}, P_{y} & \text { Pressure variations in the } x \text { and } y \text { directions } \\ p & \text { Embedding parameter } \\ \operatorname{Re} & \text { Cross-flow Reynolds number } \\ S & \text { Elastic number } \\ T & \text { Temperature } \\ \boldsymbol{T} & \text { Cauchy stress tensor } \\ T_{0}, T_{1} & \text { Temperatures of the walls } \\ t & \text { Time } \\ U & \text { Uniform injection velocity } \\ u, v, w & \text { Components of the velocity vector } \\ \boldsymbol{V} & \text { Velocity vector } \\ \theta & \text { Dimensionless temperature } \\ \tau & \text { Relaxation time } \\ \varphi_{0} & \text { Arbitrary function } \\ \rho & \text { Density }\end{array}$

\section{Introduction}

Non-Newtonian fluids in a porous surface channel have always attracted the interest of many investigators because of many applications of them in different scientific fields. Examples of these applications are the boundary layer control, transpiration cooling, 
gaseous diffusion, prevent corrosion, reactants addition and drag reduction. From a technological point of view, flows of this type are always important, especially in transpiration cooling, which is a very effective process to protect certain structural elements in turbojet and rocket engines, like combustion chamber walls, or gas turbine blades, from the influence of hot gases.

The flow of Newtonian and non-Newtonian fluids through porous channels has been investigated by numerous authors. The case of a two-dimensional, incompressible, steady, laminar suction flow of a Newtonian fluid in a parallel-walled porous channel was studied by Berman [1]. He has solved the NavierStokes equations by using a perturbation method for very low cross-flow Reynolds numbers. After his pioneering work, this problem has been studied by many researchers considering various variations in the problem $[2,3]$.

Wang and Skalak were the first persons who present the solution for a three-dimensional problem of fluid injection through one side of a long vertical channel for Newtonian fluid [4]. They have obtained a series solution valid for small values of the crossflow Reynolds numbers and a numerical solution for both small and large cross-flow Reynolds numbers. Huang re-examined Wang and Skalak's problem using a method based upon quasilinearization [5]. The same flow problem was solved for large crossflow Reynolds numbers by Ascher using a splinecollocation method. Sharma and Chaudhary reconsidered the above-mentioned problem by introducing a second order viscoelastic fluid [6,7]. They obtained the second order perturbation solution by assuming that the cross-flow Reynolds number is small. However, their results seem to be in error and their expression for pressure does not satisfy the equations of motion. In the recent years, Baris continued the last mentioned research by substituting thermodynamically compatible fluid of second grade instead of Newtonian fluid [8]. The used analytical method by Baris was traditional perturbation solution which was one of the old analytical methods.

These scientific problems are modeled by ordinary or partial differential equations and should be solved using special techniques, because in most cases, analytical solutions can't be applied to these problems. In recent years, much attention has been devoted to the newly developed methods to construct an analytic solution of these equations such as Homotopy Perturbation Method [9-11], Differential Transformation

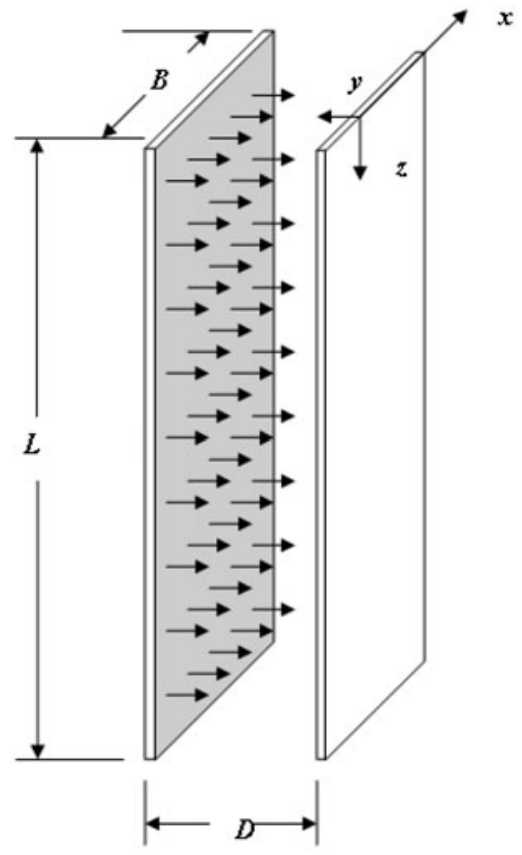

Fig. 1 Sketch of the problem under discussion

Method [12-14], and Optimal Homotopy Asymptotic Method $[15,16]$ and so on. One of these techniques is Homotopy Analysis Method (HAM), which was introduced by Liao [17-20] and has been successfully applied to solve many types of nonlinear problems [21-31].

In this paper, HAM is employed to find velocity, heat transfer and pressure variation profiles of steady three-dimensional Walter's B fluid in a vertical channel with porous wall. The major purpose of present research is to obtain new analytical technique called HAM for better analytical relations for velocity, temperature and pressure variations and to examine qualitatively the effect of elasticity of the fluid, Reynolds and Peclet number on these values. Sketch of the problem is depicted in Fig. 1.

\section{Governing equations}

The steady flow of a Walter's B fluid in a vertical channel with porous wall is considered. Figure 1 shows the physical model and coordinate system. A fluid is injected through a vertical porous plate at $y=D$ with uniform velocity $U$. The fluid strikes another vertical impermeable plate at $y=0$. It flows out through the 


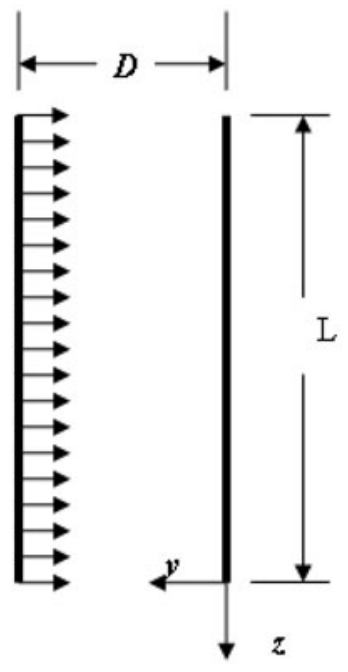

Fig. 2 Walter's B fluid flow in a vertical channel with porous wall

opening of the plates, due to the action of gravity along the $z$-axis. The distance between the walls is assumed $D$, is small compared to the dimensions of the plates, i.e. $L \gg B \gg D$. Due to this assumption the edge effects can be ignored and the isobars are parallel to the $z$-axis.

The model of Walter's B fluid is chosen for our study as it involves only one non-Newtonian parameter. The Cauchy stress tensor $\boldsymbol{T}$ in such a fluid is related to the motion in the following manner [27]:

$\boldsymbol{T}=-P \boldsymbol{I}+2 \eta_{0} e-2 k_{0} \frac{\delta e}{\delta t}$.

In this equation, $P$ is the pressure, $\boldsymbol{I}$ is the identity tensor, and the rate of strain tensor $e$ is defined by:

$2 e=\nabla v+(\nabla v)^{T}$,

where $v$ is the velocity vector, $\nabla$ is the gradient operator and $\delta / \delta t$ denotes the convected differentiation of a tensor quantity in relation to the material in motion. The convected differentiation of the rate of strain tensor is given by:

$\frac{\delta e}{\delta t}=\frac{\partial e}{\partial t}+v \cdot \nabla e-e \cdot \nabla v-(\nabla v)^{T} . e$.

Finally $\eta_{0}$ and $k_{0}$ are, respectively, the limiting viscosity at small rate of shear and the short memory coefficient which are defined through

$$
\begin{aligned}
& \eta_{0}=\int_{0}^{\infty} N(\tau) d \tau, \\
& k_{0}=\int_{0}^{\infty} \tau N(\tau) d \tau,
\end{aligned}
$$

where $N(\tau)$ is the distribution function with relaxation time $\tau$. This idealized model is a valid approximation of Walter's B fluid taking very short memory into account so that terms involving

$\int_{0}^{\infty} \tau^{n} N(\tau) d \tau, \quad n \geq 2$,

have been neglected.

In addition to (1), the basic equations of the problem are in the following form:

$\nabla . v=0$,

$\rho(v \cdot \nabla v)=\nabla \cdot T+\rho g$,

$\rho c_{p}(v \cdot \nabla T)=k \Delta T$.

Equations (6), (7) and (8) are continuity, momentum and energy equations, respectively. Where $\rho$ is the density and $\boldsymbol{g}$ is the gravitational acceleration vector. The fluid flow is assumed to be steady and laminar. The fluid is incompressible and the body force per unit mass is taken to be equal to the gravitational acceleration. Also the effects of viscous dissipation are assumed to be negligible.

Substituting Cauchy stress tensor from (1) into (7), with the aid of (2) and (3) yields:

$$
\begin{aligned}
\rho(v \cdot \nabla v)= & -\nabla P+\rho \boldsymbol{g}+\eta_{0} \nabla^{2} v \\
& -2 k_{0} v \cdot \nabla \nabla^{2} v+k_{0} \nabla^{2}(v \cdot \nabla v) .
\end{aligned}
$$

The velocity components corresponding to the $x$, $y$ and $z$ directions are respectively denoted by $u, v$ and $w$. Following [4], we look for a solution, compatible with the continuity equation, of the form:

$u=\frac{U}{D} x f^{\prime}(\eta), \quad v=-U f(\eta)$,

$w=\frac{D^{2} \boldsymbol{g} \rho}{\eta_{0}} h(\eta)$,

where $\eta=y / D$ and the prime denotes the differentiation with respect to $\eta$. The boundary conditions for the velocity field are:

$$
\begin{array}{lll}
f(0)=0, & f(1)=1, & f^{\prime}(0)=0, \\
f^{\prime}(1)=0, & h(0)=0, & h(1)=0 .
\end{array}
$$


It follows from (10) and the equation of motion that:

$$
\begin{aligned}
\frac{\partial P}{\partial x}= & \frac{U x}{D^{2}}\left(-U \rho f^{\prime 2}+U \rho f f^{\prime \prime}+\frac{U k_{0}}{D^{2}} f^{\prime \prime 2}+\frac{\eta_{0}}{D} f^{\prime \prime \prime}\right. \\
& \left.-\frac{2 U k_{0}}{D^{2}} f^{\prime} f^{\prime \prime \prime}+\frac{U k_{0}}{D^{2}} f f^{\prime \prime \prime \prime}\right) \\
\frac{\partial P}{\partial \eta}= & -U^{2} \rho f f^{\prime}-\frac{U \eta_{0}}{D} f^{\prime \prime}+\frac{3 U^{2} k_{0}}{D^{2}} f^{\prime} f^{\prime \prime} \\
& -\frac{U^{2} k_{0}}{D^{2}} f f^{\prime \prime \prime}
\end{aligned}
$$

$$
\begin{aligned}
& h^{\prime \prime}+\operatorname{Re} f h^{\prime}+\operatorname{Re} S\left(f h^{\prime \prime \prime}-f^{\prime \prime} h^{\prime}-2 f^{\prime} h^{\prime \prime}\right) \\
& \quad+1=0,
\end{aligned}
$$

where the cross-flow Reynolds number, Re, and the elastic number, $S$, are defined through, respectively

$\operatorname{Re}=\frac{U D \rho}{\eta_{0}}, \quad S=\frac{k_{0}}{\rho D^{2}}$.

Integrating (13) with respect to $\eta$, obtained equation is:

$$
\begin{aligned}
P(x, \eta)= & -\frac{1}{2} \rho U^{2} f^{2}-\frac{U \eta_{0}}{D} f^{\prime}+\frac{2 U^{2} k_{0}}{D^{2}} f^{\prime 2} \\
& -\frac{U^{2} k_{0}}{D^{2}} f f^{\prime \prime}+\varphi(x),
\end{aligned}
$$

where $\varphi(x)$ is an arbitrary function of $x$. Differentiation of the above equation with respect to $x$ yields:

$$
\frac{\partial P}{\partial x}=\frac{\partial \varphi}{\partial x} .
$$

Combining of (12) and (17) delivers:

$$
\begin{aligned}
\frac{d \varphi}{d x}= & \frac{U x \eta_{0}}{D^{3}}\left\{f^{\prime \prime \prime}+R\left(f f^{\prime \prime}-f^{\prime 2}\right)\right. \\
& \left.+R S\left(f f^{\prime \prime \prime \prime}+f^{\prime \prime 2}-2 f^{\prime} f^{\prime \prime \prime}\right)\right\} .
\end{aligned}
$$

It is apparent that the quantity in parentheses in (18) must be independent of $\eta$. Hence, the following equation for $f$ is:

$$
\begin{aligned}
& f^{\prime \prime \prime}+\operatorname{Re}\left(f f^{\prime \prime}-f^{\prime 2}\right) \\
& \quad+\operatorname{Re} S\left(f f^{\prime \prime \prime \prime}+f^{\prime \prime 2}-2 f^{\prime} f^{\prime \prime \prime}\right)=C,
\end{aligned}
$$

where $C$ is an arbitrary constant which takes the value $C=f^{\prime \prime \prime \prime}(0)+\operatorname{Re} S f^{\prime \prime 2}(0)$.
Now differentiating (19) with respect to $\eta$ to eliminate the constant $C$, gives:

$$
f^{\prime \prime \prime \prime}+\operatorname{Re}\left(f^{\prime \prime \prime} f-f^{\prime} f^{\prime \prime}\right)+\operatorname{Re} S\left(f f^{\prime \prime \prime \prime \prime \prime}-f^{\prime} f^{\prime \prime \prime \prime}\right)=0 .
$$

By using (19), $\varphi(x)$ can now be written as

$$
\varphi(x)=\frac{U \eta_{0} C}{2 D^{3}} x^{2}+P_{0},
$$

where $P_{0}$ is the constant of integration. Inserting $\varphi(x)$ from (22) into (16):

$$
\begin{aligned}
P(x, \eta)= & -\frac{1}{2} \rho U^{2} f^{2}-\frac{U \eta_{0}}{D} f^{\prime}+\frac{2 U^{2} k_{0}}{D^{2}} f^{\prime 2} \\
& -\frac{U^{2} k_{0}}{D^{2}} f f^{\prime \prime}+\frac{U \eta_{0} C}{2 D^{3}} x^{2}+P_{0} .
\end{aligned}
$$

Solving (21), leads to obtain the pressure at any point. From (23), the pressure variation in the $x$ and $y$ direction can be written in non-dimensional form as follows:

$$
\begin{aligned}
P(x) & =\frac{P(0, \eta)-P(x, \eta)}{\rho U^{2}} \\
& =-\frac{f^{\prime \prime \prime}(0)+\operatorname{Re} S f^{\prime \prime 2}(0)}{2 \operatorname{Re}}\left(\frac{x}{d}\right)^{2}, \\
P(y) & =\frac{P(x, 0)-P(x, \eta)}{\rho U^{2}} \\
& =\frac{f^{2}}{2}+\frac{f^{\prime}}{\operatorname{Re}}+S\left(f f^{\prime \prime}-2 f^{\prime 2}\right) .
\end{aligned}
$$

\section{Governing equations for temperature}

In this section, temperature field is introduced as bellow

$T=T_{0}+\left(T_{1}-T_{0}\right) \theta(\eta)$,

where $T_{0}$ and $T_{1}$ are temperatures of the impermeable and porous plates, respectively and with constant value. Substituting (10) and (26) into (8) leads to the ordinary differential equation

$\theta^{\prime \prime}+\operatorname{Pe} f \theta^{\prime}=0$,

where $\mathrm{Pe}=\rho U D c_{p} / k$ is the Peclet number. Equation (27) is solved subject to the boundary conditions

$\theta(0)=0, \quad \theta(1)=1$. 


\section{Solution using Homotopy Analysis Method}

In this section, HAM is applied to solve (14), (21) and (27) subject to boundary conditions (11) and (28). The initial guesses and auxiliary linear operators are chosen in the following form:

$f_{0}(\eta)=-2 \eta^{3}+3 \eta^{2}$,

$\theta_{0}(\eta)=\eta$

$h_{0}(\eta)=0$.

As the initial guess approximation for $f(\eta), \theta(\eta)$ and $h(\eta)$

$$
L_{1}(f)=f^{I V}, \quad L_{2}(\theta)=\theta^{\prime \prime}, \quad L_{3}(h)=h^{\prime \prime} .
$$

As the auxiliary linear operator which has the property:

$L\left(c_{1}+c_{2} \eta+c_{3} \eta^{2}+c_{4} \eta^{3}\right)=0$,

$L\left(c_{5}+c_{6} \eta\right)=0$,

$L\left(c_{7}+c_{8} \eta\right)=0$,

and $c_{i}(i=1-8)$ are constants. Let $p \in[0,1]$ denotes the embedding parameter and $\hbar$ indicates non-zero auxiliary parameters. Then, the following equations are constructed:

\section{Zeroth-order deformation equations}

$(1-P) L_{1}\left[f(\eta ; p)-f_{0}(\eta)\right]=p \hbar_{1} N_{1}[f(\eta ; p)],(32)$

$(1-P) L_{2}\left[\theta(\eta ; p)-\theta_{0}(\eta)\right]=p \hbar_{2} N_{2}[\theta(\eta ; p)]$,

$(1-p) L_{3}\left[h(\eta ; p)-h_{0}(\eta)\right]=p \hbar_{3} N_{3}[h(\eta ; p)], \quad$ (34)

$f(0 ; p)=0 ; \quad f^{\prime}(0 ; p)=0$;

$f(1 ; p)=1 ; \quad f^{\prime}(1 ; p)=1$;

$\theta(0 ; p)=0 ; \quad \theta(1 ; p)=1$;

$h(0 ; p)=0 ; \quad h(1 ; p)=0$;

$$
\begin{aligned}
N_{1}[f(\eta ; p)]= & \frac{d^{4} f(\eta ; p)}{d \eta^{4}} \\
& +\operatorname{Re}\left(f(\eta ; p) \frac{d^{3} f(\eta ; p)}{d \eta^{3}}\right.
\end{aligned}
$$

$$
\begin{aligned}
& \left.-\frac{d f(\eta ; p)}{d \eta} \frac{d^{2} f(\eta ; p)}{d \eta^{2}}\right) \\
& +\operatorname{Re} S\left(f(\eta ; p) \frac{d^{5} f(\eta ; p)}{d \eta^{5}}\right. \\
& \left.-\frac{d f(\eta ; p)}{d \eta} \frac{d^{4} f(\eta ; p)}{d \eta^{4}}\right)=0,
\end{aligned}
$$

$$
\begin{aligned}
N_{2}[\theta(\eta ; p)]= & \frac{d^{2} \theta(\eta ; p)}{d \eta^{2}} \\
& +\operatorname{Pe} f(\eta ; p) \frac{d \theta(\eta ; p)}{d \eta}=0,
\end{aligned}
$$

$$
\begin{aligned}
& N_{3}[h(\eta ; p)] \\
& =\frac{d^{2} f(\eta ; p)}{d \eta^{2}}+\operatorname{Re}\left(f(\eta ; p) \frac{d h(\eta ; p)}{d \eta}\right) \\
& \quad+\operatorname{Re} S\left(f(\eta ; p) \frac{d^{3} h(\eta ; p)}{d \eta^{3}}\right. \\
& \quad-\frac{d^{2} f(\eta ; p)}{d \eta^{2}} \frac{d h(\eta ; p)}{d \eta} \\
& \left.-2 \frac{d f(\eta ; p)}{d \eta} \frac{d^{2} h(\eta ; p)}{d \eta^{2}}\right)=0 .
\end{aligned}
$$

For $p=0$ and $p=1$ :

$$
\begin{array}{ll}
f(\eta ; 0)=f_{0}(\eta) ; & f(\eta ; 1)=f(\eta) ; \\
\theta(\eta ; 0)=\theta_{0}(\eta) ; & \theta(\eta ; 1)=\theta(\eta) ; \\
h(\eta ; 0)=h_{0}(\eta) ; & h(\eta ; 1)=h(\eta) ;
\end{array}
$$

when $p$ increases from 0 to 1 then $f(\eta ; p)$ vary from $f_{0}(\eta)$ to $f(\eta), \theta(\eta ; p)$ vary from $\theta_{0}(\eta)$ to $\theta(\eta)$ and $h(\eta ; p)$ vary from $h_{0}(\eta)$ to $h(\eta)$. By Taylor's theorem and using (41):

$$
\begin{aligned}
& f(\eta ; p)=f_{0}(\eta)+\sum_{m-1}^{\infty} f_{m}(\eta) p^{m}, \\
& f_{m}(\eta)=\frac{1}{m !} \frac{\partial^{m}(f(\eta ; p))}{\partial p^{m}} \\
& \theta(\eta ; p)=\theta_{0}(\eta)+\sum_{m-1}^{\infty} \theta_{m}(\eta) p^{m} \\
& \theta_{m}(\eta)=\frac{1}{m !} \frac{\partial^{m}(\theta(\eta ; p))}{\partial p^{m}}
\end{aligned}
$$


$h(\eta ; p)=h_{0}(\eta)+\sum_{m-1}^{\infty} h_{m}(\eta) p^{m}$,

$h_{m}(\eta)=\frac{1}{m !} \frac{\partial^{m}(h(\eta ; p))}{\partial p^{m}}$.

For simplicity, $\hbar_{1}=\hbar_{2}=\hbar_{3}=\hbar$ is supposed, which $\hbar$ is chosen in such a way that these three series are convergent at $p=1$. Therefore, through (42)-(44) below equations are obtained:

$f(\eta)=f_{0}(\eta)+\sum_{m-1}^{\infty} f_{m}(\eta)$,

$\theta(\eta)=\theta_{0}(\eta)+\sum_{m-1}^{\infty} \theta_{m}(\eta)$,

$h(\eta)=h_{0}(\eta)+\sum_{m-1}^{\infty} h_{m}(\eta)$.

mth-order deformation equations

$$
\begin{aligned}
& L\left[f_{m}(\eta)-\chi_{m} f_{m-1}(\eta)\right]=\hbar R_{m}^{f}(\eta) \\
& f_{m}(0)=f_{m}^{\prime}(0)=f_{m}(1)=f_{m}^{\prime}(1)=0 \\
& R_{m}^{f}(\eta)=f_{m-1}^{I V}+\operatorname{Re} \sum_{n=0}^{m-1} f_{m-1-n} f_{n}^{\prime \prime \prime}-f_{m-1-n}^{\prime} f_{n}^{\prime \prime} \\
& \quad+\operatorname{Re} S \sum_{n=0}^{m-1} f_{m-1-n} f_{n}^{V}-f_{m-1-n}^{\prime} f_{n}^{I V}, \\
& L\left[\theta_{m}(\eta)-\chi_{m} \theta_{m-1}(\eta)\right]=\hbar R_{m}^{\theta}(\eta) \\
& \theta_{m}(0)=\theta_{m}(1)=0, \\
& R_{m}^{\theta}(\eta)=\theta_{m-1}^{\prime \prime}+\sum_{n=0}^{m-1} \operatorname{Pe} f_{m-1-n} \theta_{n}^{\prime}, \\
& L\left[h_{m}(\eta)-\chi_{m} h_{m-1}(\eta)\right]=\hbar R_{m}^{h}(\eta) \\
& h_{m}(0)=h_{m}(1)=0, \\
& R_{m}^{h}(\eta)=h_{m-1}^{\prime \prime}+\operatorname{Re} \sum_{n=0}^{m-1} f_{m-1-n} h_{n}^{\prime} \\
& \quad+\sum_{n=0}^{m-1} \operatorname{Re} S\left(f_{m-1-n} h_{n}^{\prime \prime \prime}-h_{m-1-n}^{\prime} f_{n}^{\prime \prime}\right. \\
& \left.\quad 2 f_{m-1-n}^{\prime} h_{n}^{\prime \prime}\right)+1,
\end{aligned}
$$

$\chi_{m}= \begin{cases}0, & m \leq 1 \\ 1, & m>1\end{cases}$

\section{Convergence of HAM}

HAM provides us with a great freedom in choosing the solution of a nonlinear problem by different base functions. This has a great effect on the convergence region because the convergence region and the rate of a series are chiefly determined by the base functions used to express the solution. Therefore, a nonlinear problem could be approximated more efficiently by ensuring its convergency. The convergence and rate of approximation for the HAM solution depends on the value of auxiliary parameter $\hbar$ strongly. By means of the so-called $\hbar$-curves, it is easy to find out the so-called valid regions of auxiliary parameters to gain a convergent solution series. According to Figs. 3 to 6 , the convergence ranges of $f^{\prime \prime}(0), \theta^{\prime}(0)$ and $h^{\prime}(0)$ are variable for different values of parameters.

\section{Results and discussion}

In this section, based on the Homotopy Analysis Method (HAM) solution which presented in Sect. 4, the tangential, normal and axial velocities of the steady flow of a Walter's B fluid in a vertical channel are obtained.

In Figs. 7-9, the functions which correspond to the velocity components have been plotted versus $\eta$ for two different values of the cross-flow Reynolds number (Re), with the elastic number $S$ as a parameter. For low values of the cross-flow Reynolds number, e.g. $\operatorname{Re}=1$, the velocity profiles in the viscoelastic fluid case, are indistinguishable from those in the Newtonian fluid cases and so they are not presented.

Figure 7 depicts the normal velocity component for various values of the elastic number when $R e$ is fixed at 10 and 20, respectively. As evident, by increasing of the elastic number, the normal velocity intensifies.

Figure 8 illustrates the effect of elastic number on tangential velocity profiles for the same values of cross-flow Reynolds number and the elastic number. It is obvious from this figure that the tangential velocity profile behavior is different from approximately 


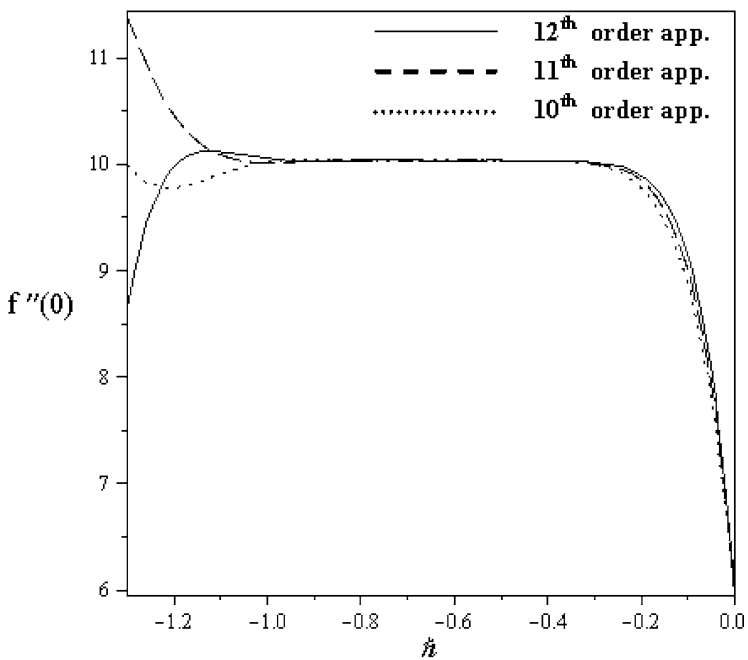

Fig. 3 The $\hbar$-validity for $f(\eta)$, when $\operatorname{Re}=10, S=0$

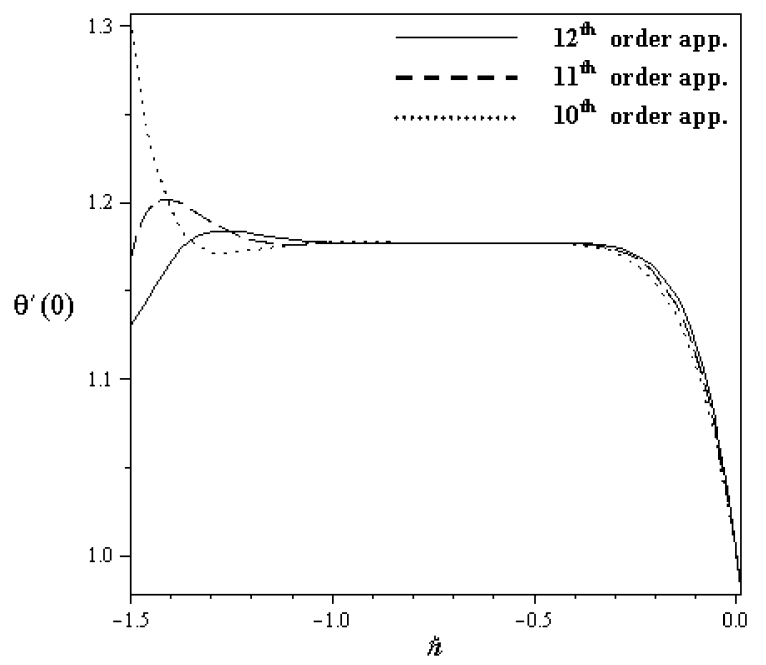

Fig. 4 The $\hbar$-validity for $\theta(\eta)$, when $\operatorname{Re}=10, S=0$

$\eta=0.4$ to the $\eta=1$. According to this figure, the increasing of the elastic number enhances the maximum of tangential velocity and moves it away from porous plate. Also increasing the cross flow Reynolds number switch the maximum velocity point to further distance from the porous surface. This is due to increment of shear stresses on impermeable surface of the channel.

Axial velocity which is due to gravity force has been shown in Fig. 9 when Re is keeping fixed in 10. It is obvious that the increasing of elastic parameter en-

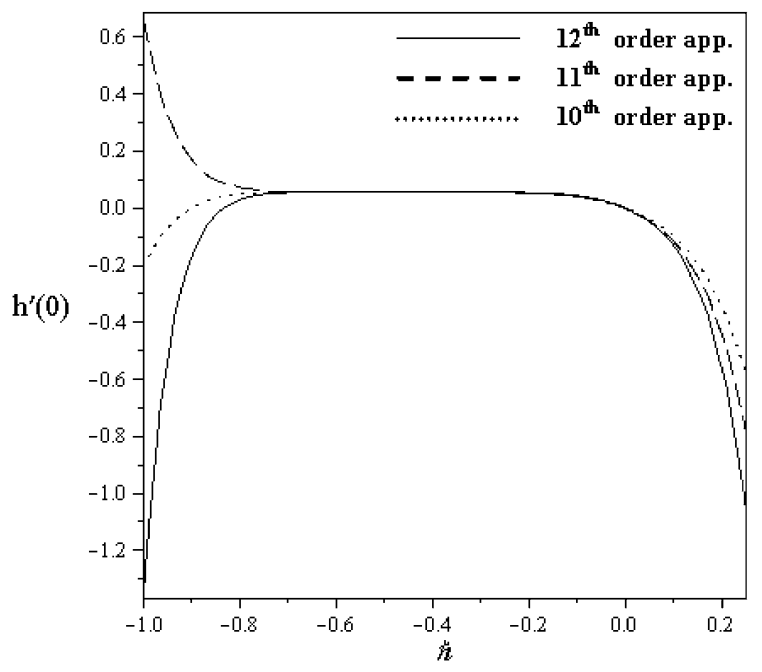

Fig. 5 The $\hbar$-validity for $h(\eta)$, when $\operatorname{Re}=10, S=0.012$

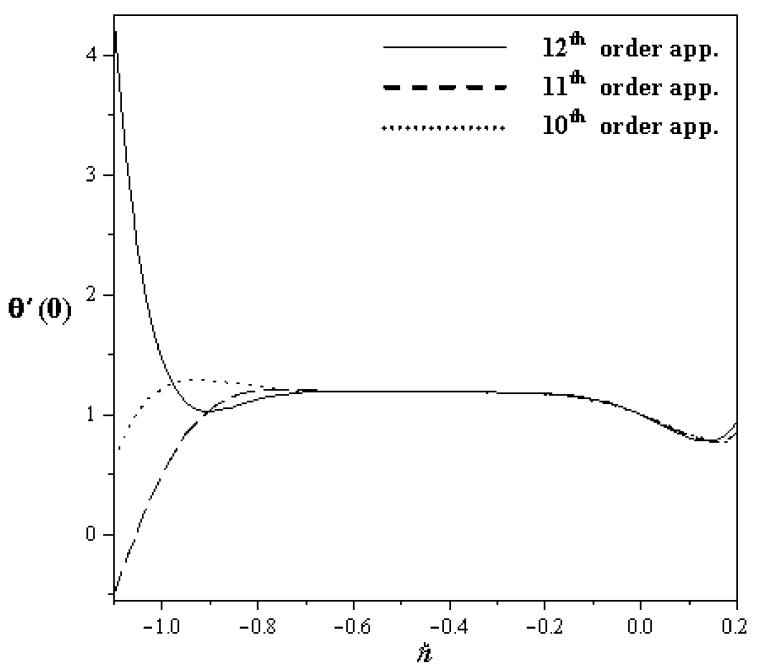

Fig. 6 The $\hbar$-validity for $\theta(\eta)$, when $\operatorname{Re}=20, S=0$

hances the maximum of axial velocity. Therefore, the value of axial velocity for viscoelastic fluids is more than that for Newtonian fluids.

In Fig. 10, the effects of suction and injection have been investigated. As it is shown by contours in Fig. 10, velocity contour concentration in $\operatorname{Re}=10$ occurs approximately in $\eta=0.4$ and for $\operatorname{Re}=-10$ is approximately in $\eta=0.8$. Regarding to this figure, the position of maximum tangential velocity gets closer to the porous surface when Reynolds number has a negative value. Vectors of tangential velocity are depicted in Fig. 11. For $\operatorname{Re}=10$, in $\eta=0.4$ size of vectors are 


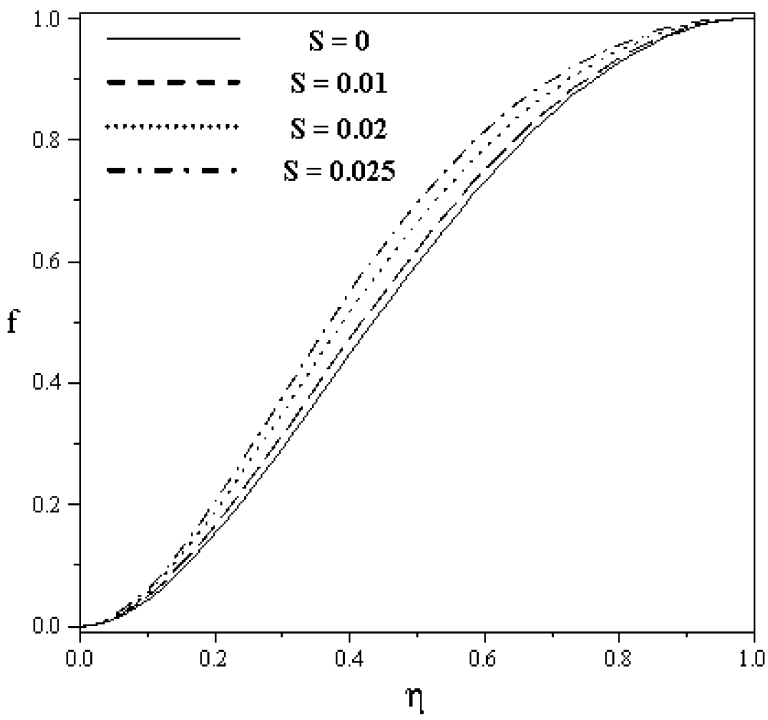

(a)

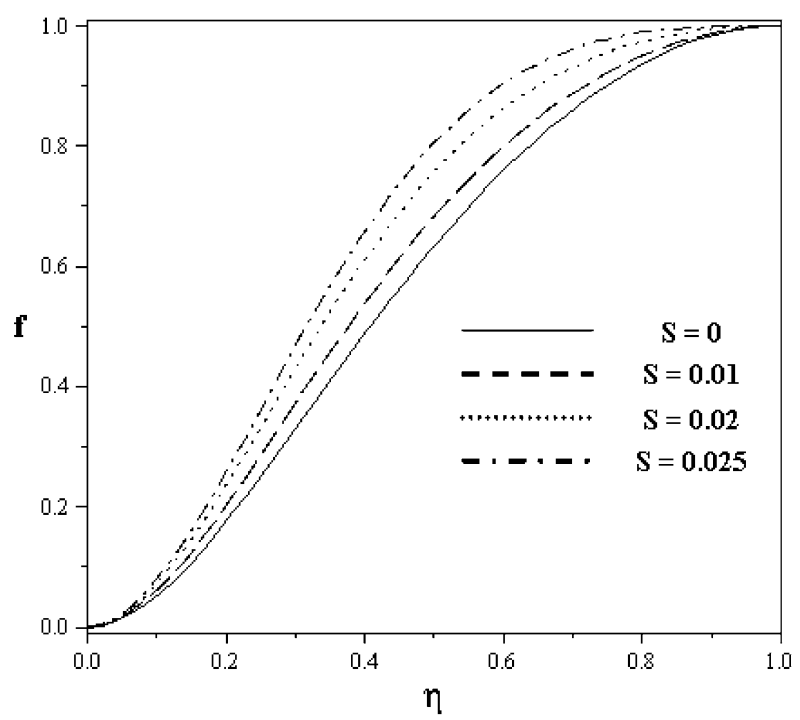

(b)

Fig. 7 Normal velocity profile when (a) $\operatorname{Re}=10,(\mathbf{b}) \operatorname{Re}=20$

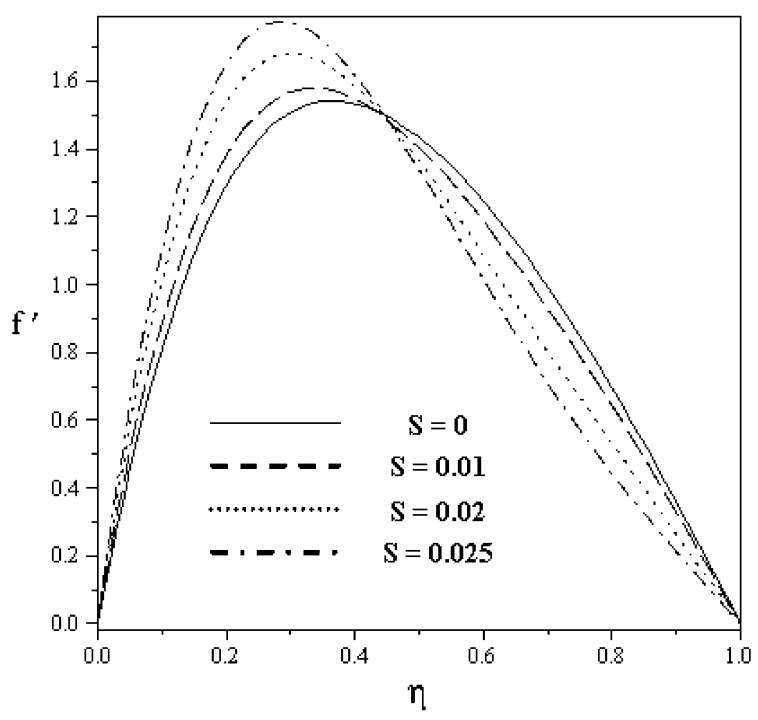

(a)

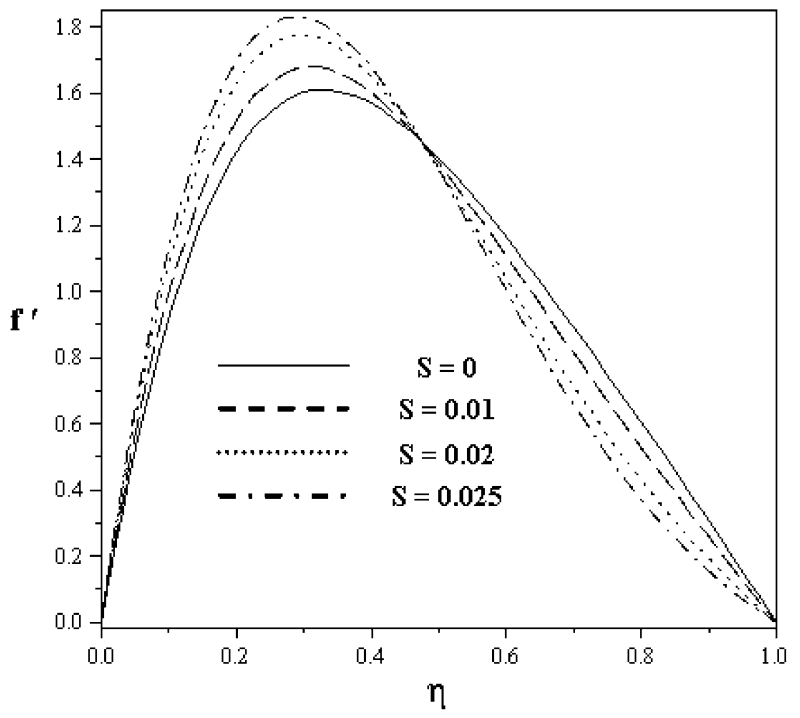

(b)

Fig. 8 Tangential velocity profile for (a) $\operatorname{Re}=10,(\mathbf{b}) \operatorname{Re}=20$

in maximum values. This is corresponding to velocity contours presented in Fig. 10. The same results can be obtained for $\operatorname{Re}=-10$.

Figure 12 depicts the profiles of temperature difference in viscoelastic fluid in a vertical channel with porous wall. In this figure, variation of temperature is shown when $S=0.012$ and Reynolds number is keep- ing fixed in 10 and 20 that the effect of Peclet number on temperature profile is shown. According to definition of Peclet number, increasing of Peclet is equal to increasing of uniform injection velocity. Due to the convection effects, increasing of Peclet number leads to intensify the temperature distribution in the channel. 
Also Figs. 13(a) and 13(b) present the pressure variations in the $x$ and $y$ directions, respectively when $\operatorname{Re}=10$. From the evident, the pressure variations will decrease with increasing of elastic number. This is due to the pressure increment along the $x$ axis of the channel which leads to decreasing of pressure difference between origin and farther points along $x$ axis.

Stream functions of fluid flow for two cases of suction and injection are displayed in Fig. 14. Injection

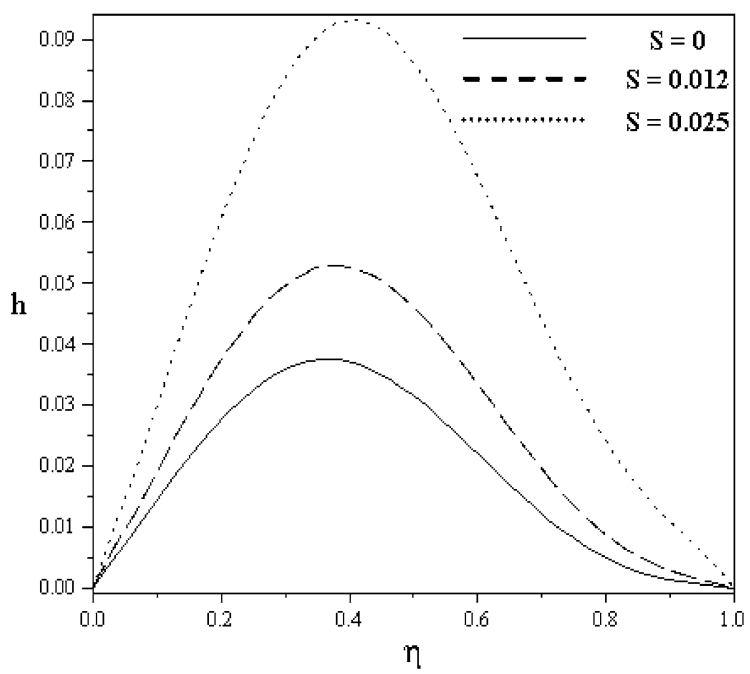

Fig. 9 Axial velocity profile for $\mathrm{Re}=10$

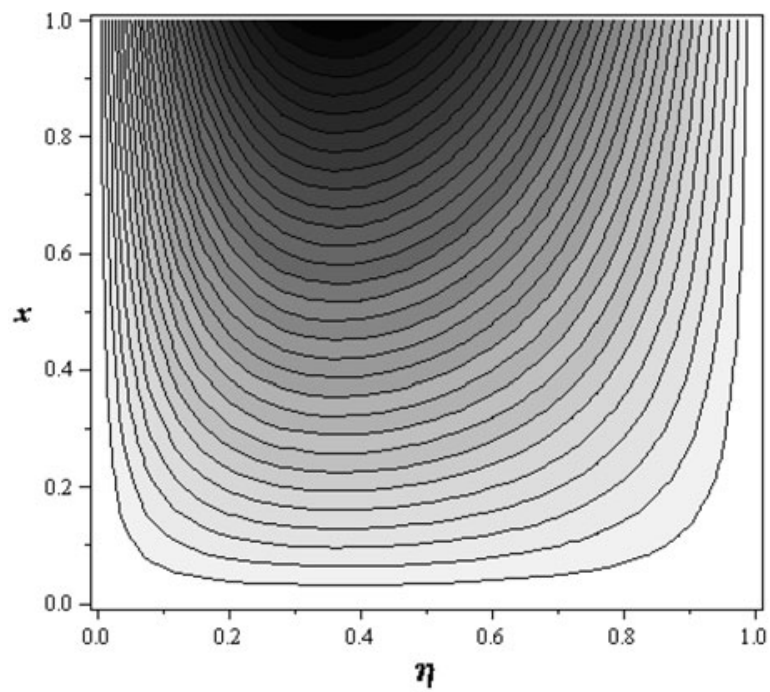

(a) has more concentration stream functions than suction and due to injection streamlines are closer to the origin in comparison with suction.

\section{Conclusion}

In this paper, the steady three-dimensional flow of a Walter's B fluid in a vertical channel with porous wall has been studied using Homotopy Analysis Method (HAM) to present an analytical solution for the flow and temperature field. It is supposed that the fluid is injected into the channel through one side of the channel. The governing equations of problem are reduced to a set of nonlinear ordinary differential equations using similarity transformation and are solved by means of HAM.

Most important results of this research can be outlined as below:

- The elastic element of the fluid increases the normal velocity at any point.

- Tangential velocity increases with an increase in the elastic number $S$, up to approximately $\eta=0.4$ and thereafter decreases with increasing $S$.

- With an increase in the value of the cross-flow Reynolds number, the point at which maximum ve-

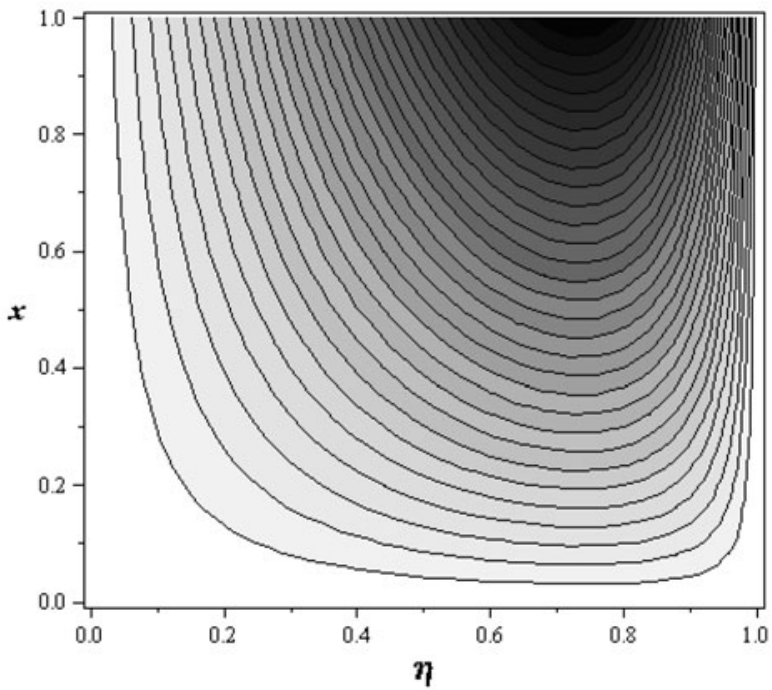

(b)

Fig. 10 Tangential velocity contours for (a) $\operatorname{Re}=10,(\mathbf{b}) \operatorname{Re}=-10$ 


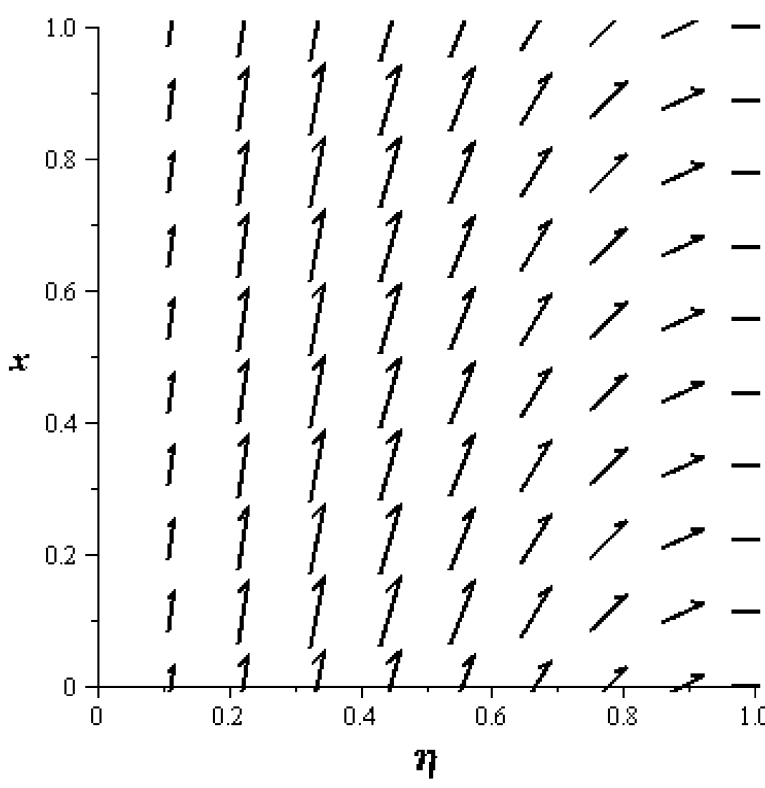

(a)

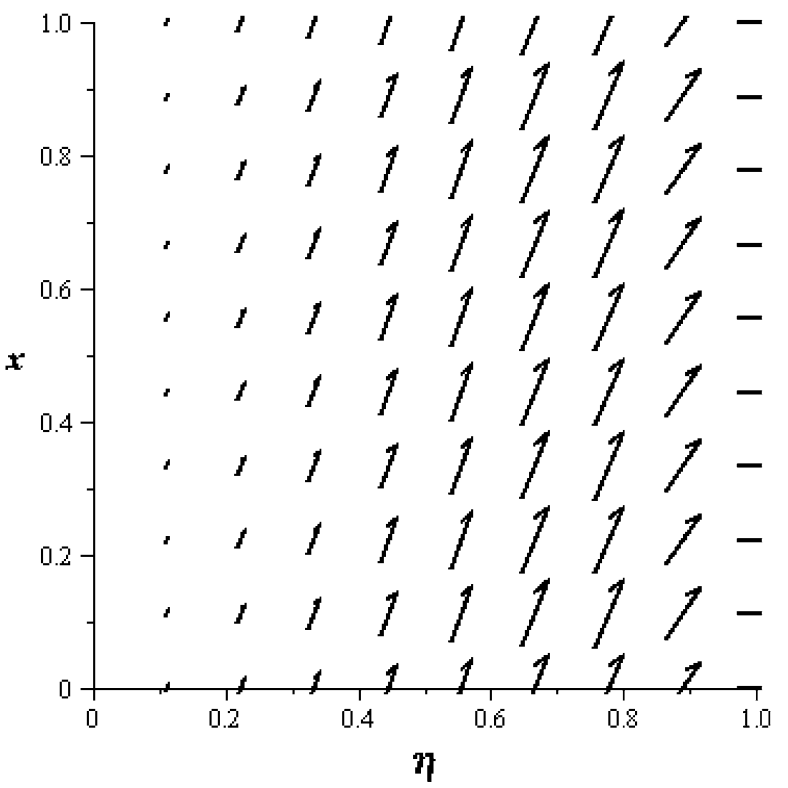

(b)

Fig. 11 Tangential velocity vectors for $(\mathbf{a}) \operatorname{Re}=10,(\mathbf{b}) \mathrm{Re}=-10$

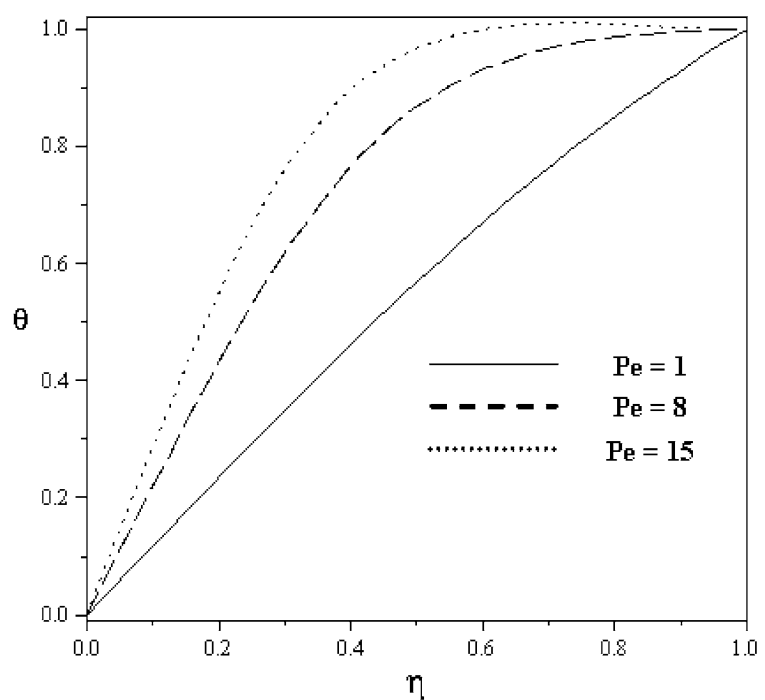

(a)

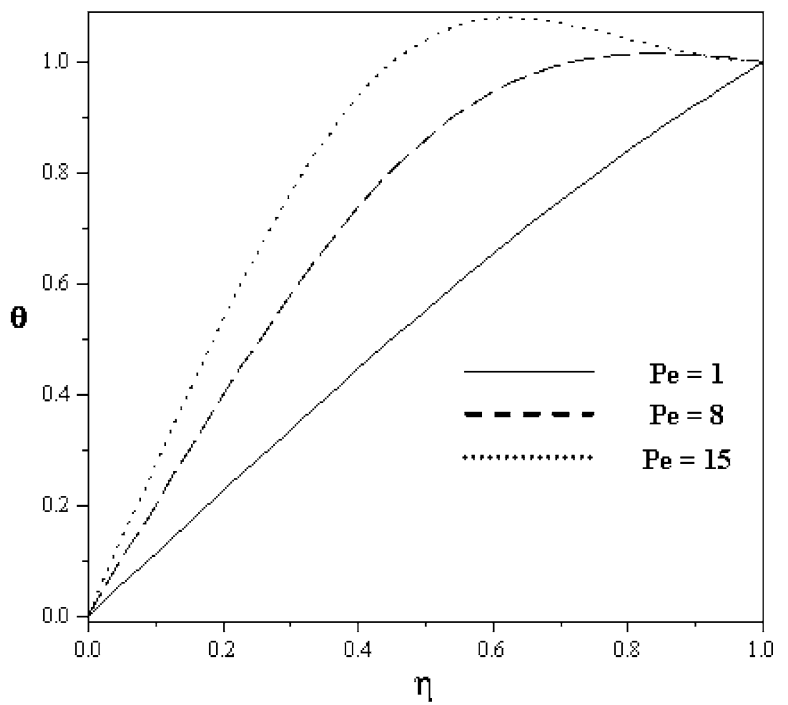

(b)

Fig. 12 Temperature variation when (a) $\operatorname{Re}=10$, (b) $\operatorname{Re}=20$

locity occurs moves away from the porous plate. Moreover, the elastic elements of the fluid make this point closer to the impermeable wall.

- When $\operatorname{Re}=10$, that the axial velocity for a viscoelastic fluid is more than that for a Newtonian fluid.
- In Re $=10$ increasing of Peclet number is cause of increment of temperature distribution of the fluid. When $\operatorname{Re}=20$, the same result is obtained.

- The elasticity of the fluid decreases the pressure variations in both directions. 


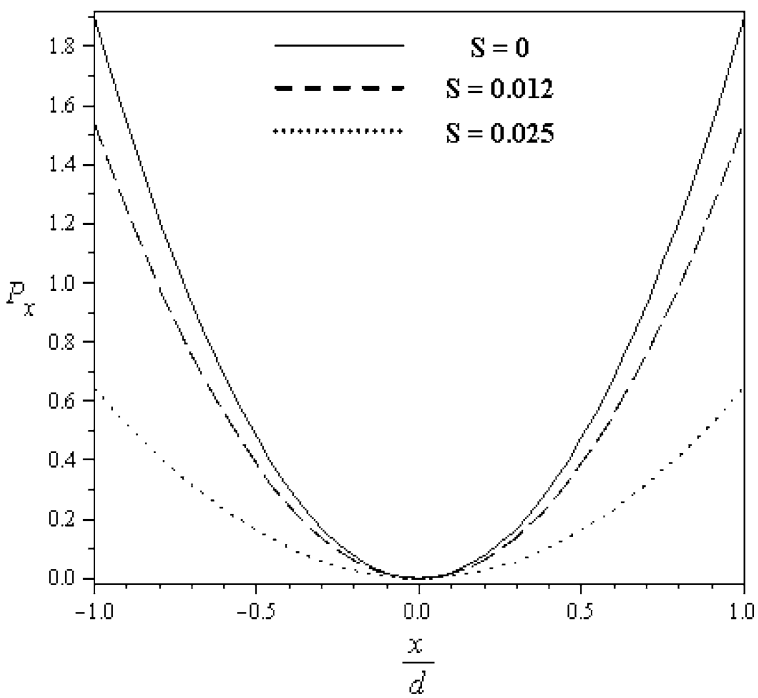

(a)

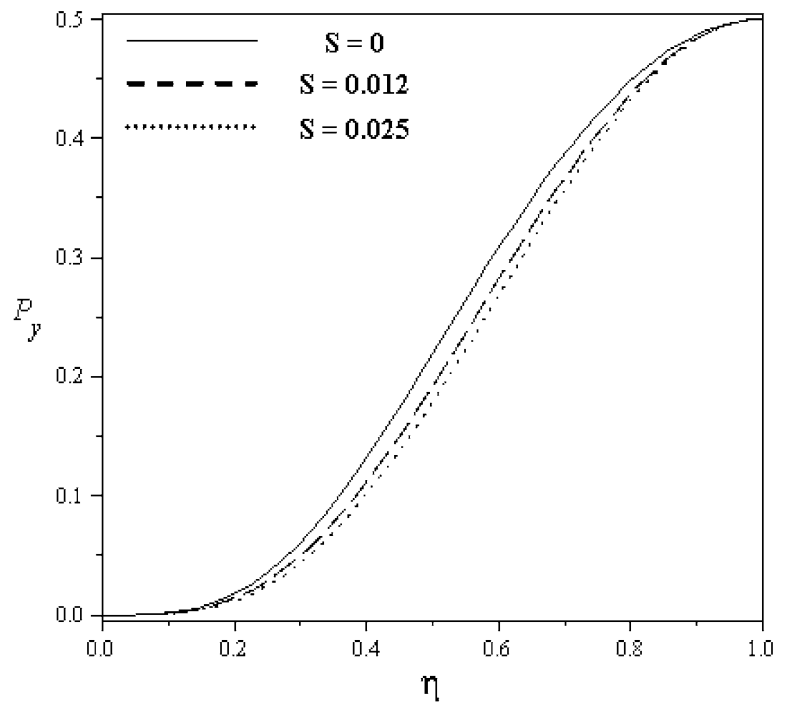

(b)

Fig. 13 Pressure variation when $\operatorname{Re}=10$ (a) in $x$ direction, (b) in $y$ direction

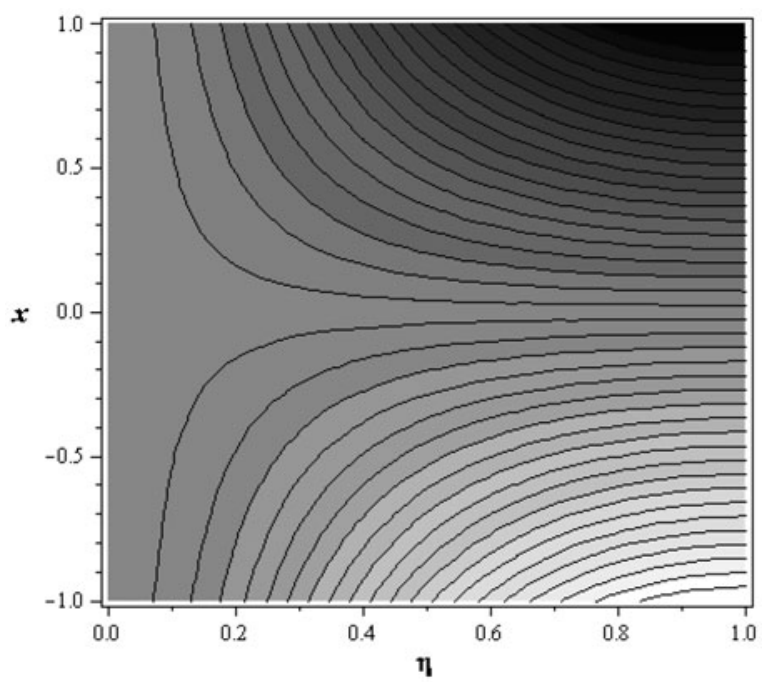

(a)

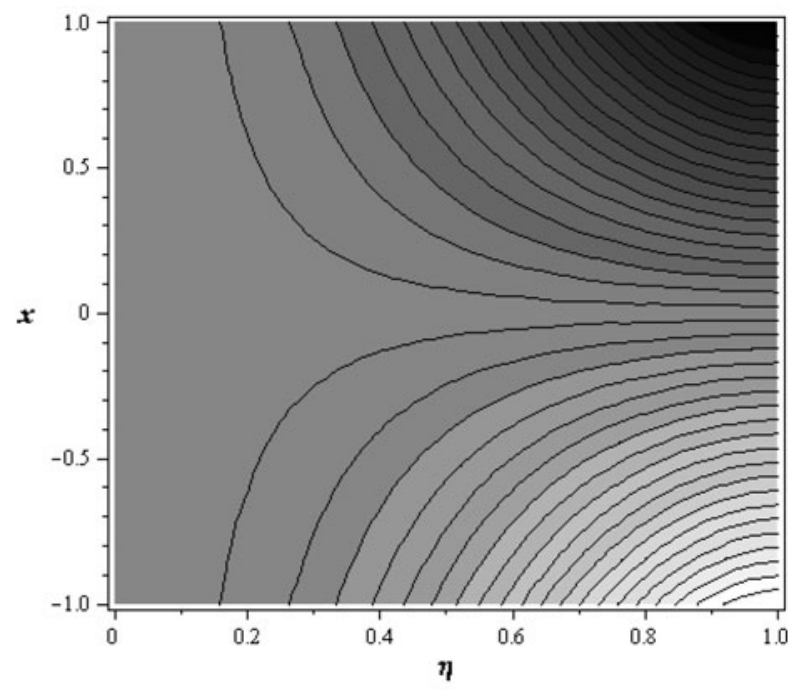

(b)

Fig. 14 Stream function of fluid flow (a) $\operatorname{Re}=10$, (b) $\operatorname{Re}=-10$

- Streamlines in injection is closer to the origin of the coordinate than suction.

Open Access This article is distributed under the terms of the Creative Commons Attribution Noncommercial License which permits any noncommercial use, distribution, and reproduction in any medium, provided the original author(s) and source are credited.

\section{References}

1. Berman AS (1953) Laminar flow in channels with porous walls. J Appl Phys 24:1232-1235

2. Cox SM (1991) Two dimensional flow of a viscous fluid in a channel with porous walls. J Fluid Mech 227:1-33

3. Choi JJ, Rusak Z, Tichy JA (1999) Maxwell fluid suction flow in a channel. J Non-Newtonian Fluid Mech $85: 165-187$ 
4. Wang CY, Skalak F (1974) Fluid injection through one side of a long vertical channel. AIChE J 20:603-605

5. Huang CL (1978) Application of quasilinearization technique to the vertical channel flow and heat convection. Int $\mathrm{J}$ Non-Linear Mech 13:55-60

6. Ascher U (1980) Solving boundary value problems with a spline-collocation code. J Comput Phys 34:401-413

7. Sharma PR, Chaudhary RC (1982) Fluid injection of a Rivlin-Ericksen fluid through one side of a long vertical channel. Bull Tech Univ Istanbul 35:175-185

8. Baris S (2001) Injection of a non-Newtonian fluid through one side of a long vertical channel. Acta Mech 151:163-170

9. He JH (2005) Homotopy perturbation method for bifurcation on nonlinear problems. Int J Non-Linear Sci Numer Simul 8:207-208

10. Ganji DD, Rajabi A (2006) Assessment of homotopyperturbation and perturbation methods in heat radiation equations. Int Commun Heat Mass Transf 33:391-400

11. Ganji DD, Rafei M, Sadighi A, Ganji ZZ (2009) A comparative comparison of He's method with perturbation and numerical methods for nonlinear vibrations equations. Int $\mathbf{J}$ Nonlinear Dyn Eng Sci 1(1):1-20

12. Zhou JK (1986) Differential transformation and Its applications for electrical circuits. Huarjung University Press, Wuuhahn (in Chinese)

13. Joneidi AA, Ganji DD, Babaelahi M (2009) Differential transformation method to determine fin efficiency of convective straight fins with temperature dependent thermal conductivity. Int Commun Heat and Mass Transf 36:757-762

14. Babaelahi M, Ganji DD, Joneidi AA (2009) Analysis of velocity equation of steady flow of a viscous Incompressible fluid in channel with porous walls. Int $\mathbf{J}$ Numer Methods Fluids. doi:10.1002/fld.2114

15. Marinca V, Herisanu N (2008) Application of Optimal Homotopy Asymptotic Method for solving nonlinear equations arising in heat transfer. Int Commun Heat Mass Transf 35:710-715

16. Joneidi AA, Ganji DD, Babaelahi M (2009) Micropolar flow in a porous channel with high mass transfer. Int Commun Heat and Mass Transf 36(10):1082-1088

17. Liao SJ (1992) The proposed homotopy analysis technique for the solution of nonlinear problems. PhD thesis, Shanghai Jiao Tong University

18. Liao SJ (2003) Beyond perturbation: introduction to the homotopy analysis method. Chapman \& Hall, CRC Press, Boca Raton
19. Liao SJ (2003) On the analytic solution of magnetohydrodynamic flows of non-Newtonian fluids over a stretching sheet. J Fluid Mech 488:189-212

20. Liao SJ (2004) On the homotopy analysis method for nonlinear problems. Appl Math Comput 147:499-513

21. Hayat T, Khan M, Ayub M (2004) On the explicit analytic solutions of an Oldroyd 6-constant fluid. Int J Eng Sci 42:123-135

22. Hayat T, Khan M, Ayub M (2004) Couett and Poisevill flow of an oldroyd 6-constant fluid with magnetic field. J Math Anal Appl 298:225-244

23. Joneidi AA, Domairry G, Babaelahi M, Mozaffari M (2009) Analytical treatment on Magnetohydrodynamic (MHD) flow and heat transfer due to a stretching hollow cylinder. Int $\mathrm{J}$ Numer Methods Fluids. doi: $10.1002 /$ fld. 2087

24. Joneidi AA, Domairry G, Babaelahi M (2010) Analytical treatment of MHD free convective flow and mass transfer over a stretching sheet with chemical reaction. J Taiwan Inst Chem Eng 41(1), 35-43

25. Farzaneh-Gord Mahmood, Joneidi AA, Haghighi B (2010) Investigating the effects of the important parameters on MHD flow and heat transfer over a stretching sheet. Proc Inst Mech Ehg, E J Process Mech Eng 224(1):1-9

26. Joneidi AA, Domairry G, Babaelahi M (2010) Three analytical method applied to Jeffery-Hamel flow. Commun Nonlinear Sci Numer Simul. doi:10.1016/j.cnsns. 2009.12.023

27. Mehmood A, Ali A, Shah T (2008) Heat transfer analysis of unsteady boundary layer flow by homotopy analysis method. Commun Nonlinear Sci Numer Simul 13(5):902-912

28. Tan Y, Abbasbandy S (2008) Homotopy analysis method for quadratic Riccati differential equation. Commun Nonlinear Sci Numer Simul 13(3):539-546

29. Hayat T, Sajid M, Ayub M (2007) A note on series solution for generalized Couette flow. Commun Nonlinear Sci Numer Simul 12(8):1481-1497

30. Abbasbandy S (2007) The application of homotopy analysis method to solve a generalized Hirota-Satsuma coupled KdV equation. Phys Lett A 361(6):478-483

31. Abbasbandy S (2008) Soliton solutions for the FitzhughNagumo equation with the homotopy analysis method. Appl Math Model 32(12):2706-2714 